\title{
Siglenverzeichnis / List of Sigla
}

AASS

$\mathrm{AB}$

ACO

$\mathrm{AJPh}$

AnTard

BAR

BBA

BBS

$\mathrm{BF}$

BHG

BMGS

BNJ

BS1

BV

Byz

BZ

CAG

CC SG

CC SL

CFHB

$\mathrm{CJ}$

$\mathrm{CP}$

CPG

CSHB

DOP

DOS

DOT

EEBS/EEB $\Sigma$

EO

FMSt

GRBS

HdAW

Hell

HSCP
Acta Sanctorum

Analecta Bollandiana

Acta conciliorum oecumenicorum

American Journal of Philology

Antiquité tardive

British Archaeological Reports

Berliner Byzantinistische Arbeiten

Berliner Byzantinistische Studien

Byzantinische Forschungen

Bibliotheca Hagiographica Graeca

Byzantine and Modern Greek Studies

Byzantinisch-Neugriechische Jahrbücher

Byzantinoslavica

Byzantina Vindobonensia

Byzantion

Byzantinische Zeitschrift

Commentaria in Aristotelem Graeca

Corpus christianorum, series Graeca

Corpus christianorum, series Latina

Corpus fontium historiae byzantinae

Classical Journal

Classical Philology

Clavis patrum Graecorum

Corpus scriptorum historiae Byzantinae

Dumbarton Oaks Papers

Dumbarton Oaks Studies

Dumbarton Oaks Texts

Epeteris hetaireias Byzantinon spudon /

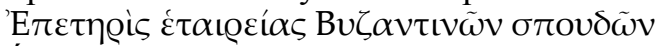

Échos d'Orient

Frühmittelalterliche Studien

Greek, Roman and Byzantine Studies

Handbuch der Altertumswissenschaften

Hellenika / 'E $\lambda \lambda \eta v \iota \kappa \alpha ́$

Harvard Studies in Classical Philology 
$\mathrm{HZ}$

IRAIK

$\mathrm{JbAC}$

JECS

JÖB

JRAS

JRS

JThS

LBG

LexMa

LThK

MBM

OCA

OCP

ODB

PBE

PG

PL

PLP

PLRE

PmbZ

PO

$P \& P$

$\mathrm{RE}$

REB

REG

RHM

ROC

RSBN

$\mathrm{SC}$

SM

Spec

StT

SubHag

TAPA

ThLL

TLG
Historische Zeitschrift

Izvestija Russkago Archeologičeskago Instituta v Konstantinoplo'e

Jahrbuch für Antike und Christentum

Journal of Early Christian Studies

Jahrbuch der Österreichischen Byzantinistik

Journal of the Royal Asiatic Society of Great Britain and Ireland

Journal of Roman Studies

Journal of Theological Studies

Lexikon zur byzantinischen Gräzität, Wien 1994-

Lexikon des Mittelalters

Lexikon für Theologie und Kirche

Miscellanea Byzantina Monacensia

Orientalia Christiana Analecta

Orientalia Christiana Periodica

A. Kazhdan (Hrsg.), The Oxford Dictionary of Byzantium, Oxford 1991.

Prosopography of the Byzantine Empire

Patrologia Graeca

Patrologia Latina

Prosopographisches Lexikon der Palaiologenzeit

Prosopography of the Later Roman Empire

Prosopographie der mittelbyzantinischen Zeit

Patrologia Orientalis

Past and Present

Pauly's Real-Encyclopaedie der classischen

Altertumswissenschaft

Revue des études byzantines

Revue des études grecques

Römische Historische Mitteilungen

Revue de l'Orient chrétien

Rivista di Studi Bizantini e Neoellenici

Sources chrétiennes

Studi medievali

Speculum

Studi e testi

Subsidia Hagiographica

Transactions and Proceedings of the American

Philological Association

Thesaurus Linguae Latinae

Thesaurus Linguae Graecae (www.tlg.uci.edu) 
$\mathrm{TM}$

TRE

VV

WBS

$\mathrm{WdF}$

WSt

ZRVI
Collège de France. Centre de recherche d'histoire et civilisation de Byzance. Travaux et Mémoires Theologische Realenzyklopädie Vizantijskij Vremennik

Wiener Byzantinistische Studien Wege der Forschung Wiener Studien Зборник радова византолошког института / Zbornik radova vizantološkog instituta 
